\title{
EFFECT OF FREE SURFACE BOUNDARY AND WALL FLEXIBILITY IN SEISMIC DESIGN OF LIQUID STORAGE STEEL TANKS
}

\author{
Rahul A $\mathbf{R}^{1}$, Sreeja $\mathbf{S}^{\mathbf{2}}$ \\ ${ }^{1}$ M.Tech Student, Civil Department, ICET, Kerala, India \\ ${ }^{2}$ Assistant Professor, Civil Department, ICET, Kerala, India
}

\begin{abstract}
Fluid Structure Interaction (FSI) itself is a vast and extensive discipline. It originated from studies of aero and hydro-elasticity, which are often related to aeronautics and aerospace as well as nuclear industries. In practice, within the scope of nuclear, civil, aerospace, ocean, chemical and mechanical engineering, there are many terminologies involved, ie., flow induced vibration, aero-elasticity, hydro-elasticity, fluid structure interaction and fluid solid interaction. Typical problems include structure interaction with surface and sound waves and vibrations and stabilities of cables, pipes, plates and shells. In this paper, the effect of fluid structure interaction on the modal characteristics of a cylindrical steel water tank with and without free surface effect is considered. Acoustic structure interaction using unsymmetric pressure based formulation is used to solve the coupled system using FEM and the procedure is validated using results from published literature. Two tank models (shallow and tall) are modeled using ANSYS and modal analysis was done by considering different conditions like with slosh and without slosh. The effect of fluid mass on the convective and impulsive modes of tall and shallow aspect ratio tanks is shown. Parametric study is done for different fluid levels to characterize the variation of slosh frequencies in both rigid and flexible wall conditions. Free surface is considered in fluid alone model to predict the slosh frequencies employing rigid wall boundary. Then slosh frequencies got from both rigid and flexible wall conditions are compared with design data frequency tabulated from the GSDMA Guidelines. From this we can say that the flexibility of tank wall has a greater effect on the slosh frequencies.
\end{abstract}

Key Words: Fluid-structure Interaction, Impulsive mode, Convective mode, Slosh frequency

\section{INTRODUCTION}

Fluid Structure Interaction (FSI) is defined as the interaction of some deformable or movable structure with an internal or surrounding flow. The important aspect of FSI is that there must be genuine interaction between the fluid and solid component. This implies that there is a transfer of energy from fluid to the solid and vice versa. Fluid structure interaction becomes particularly important when the liquid is almost incompressible and deformation on the solid cannot be neglected.

A literature survey has been conducted on seismic design of liquid storage tanks and its simulation. Most of the papers are having experimental evaluation of the structure with changes in shape and height. With the addition of another structure like roof on the tank also contribute significant effects on to it. Dynamic analysis of different shapes of tanks with varying quantities has been studied by various researchers.

M. Moslemi et al, identified the major parameters which affects the dynamic response of acoustic structures and found the relation between these major parameters. Sloshing of fluid free surface, vertical ground acceleration, tank wall flexibility, tank aspect ratio, and base fixity are the major parameters. M. Amiri et al introduced a series of ambient vibration tests on three tall liquid storage tanks with same height and different radius, to determine the natural frequencies and, the modes of the vibration. Juan C. Virella et al introduced the fundamental impulsive modes of cylindrical tanks which are anchored to the foundation under horizontal earthquake motion. The roof and walls are modelled with shell elements and the liquid is modelled using two different techniques such as acoustic finite elements and added mass formulation. Juan C. Virella et al obtained the pressure waves acting on the walls of the tank for the first three sloshing modes through linear and nonlinear wave theory.

The literature survey gives a deep insight to the effects of various parameters on seismic structures and impact of different shapes on the natural frequency of the system, location of liquid storage tanks and the analysis on them. Jean-françois sigrista et al deals with numerical developments in the ANSYS finite element codes to create fluid-structure interaction and dynamic analysis with pressure based FE formulation, using spectral and modal techniques. Fluid-structure symmetric formulations for hydro-elastic and elasto-acoustic problems are implemented to enhance the modelling possibilities within the ANSYS code. For a fluid-structure coupled system, linear dynamic analysis with modal projection techniques can be achieved through the usage of symmetric formulation. The basic principles of those methods are briefly explained in the section of FSI.

The main aim of the analysis is to evaluate the dynamic interaction between fluid and structure. The main reason for the study is better predictive Finite Element model development for design of structures which are prone to earthquake. By knowing the natural frequency and mode shapes, the structures which are prone to common frequencies of earthquake can be better designed. Parametric 
study is conducted by considering different wall flexibility, liquid level, tank dimensions etc. to characterize their significance in seismic response.

In this work, we are considering two models a) Shallow tank, b) Tall tank. ANSYS 16 is used for finite element analysis. Dimensions of the models are shown below.

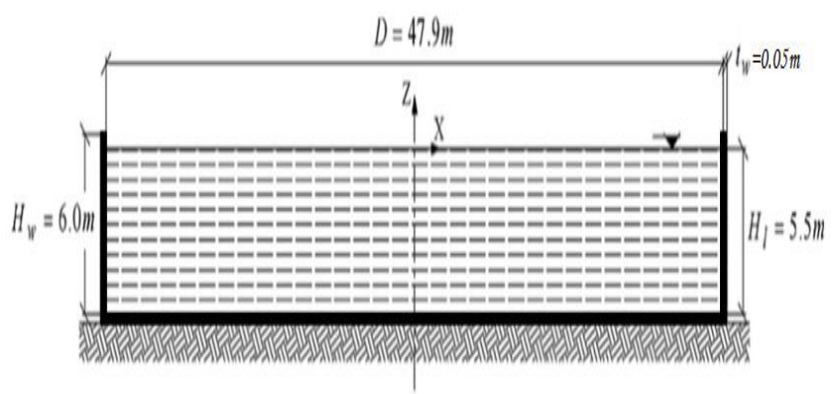

Fig -1: Schematic diagram of Shallow tank model

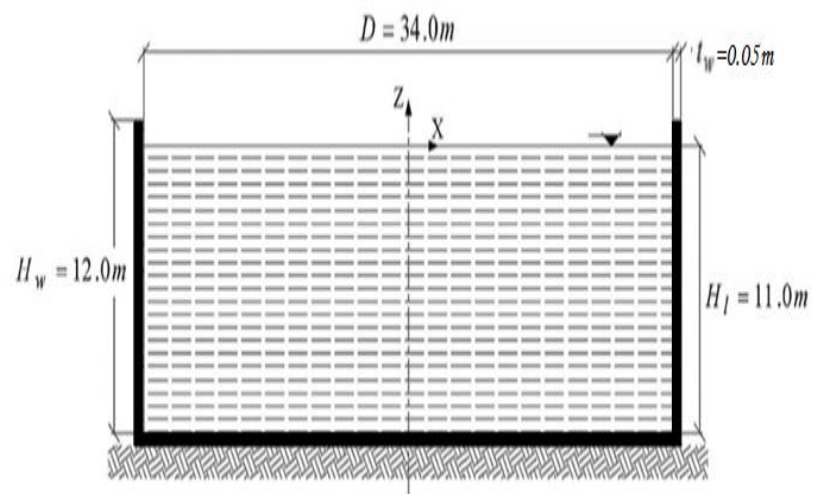

Fig -2: Schematic diagram of Tall tank model

\section{PROBLEM FORMULATION}

\subsection{Modeling}

Three dimensional finite element models are developed to study the behavior liquid storage tanks. Modeling and analysis was done using ANSYS 16. The tank structure is modeled using four noded isoparametric quadrilateral SHELL181 Element and the fluid domain is modeled using Fluid30 Element.

Properties:

Table -1: Input Properties

\begin{tabular}{|c|c|}
\hline Steel & Fluid \\
\hline Density $=7850 \mathrm{Kg} / \mathrm{m}^{3}$ & Density $=1000 \mathrm{Kg} / \mathrm{m}^{3}$ \\
\hline $\begin{array}{c}\text { Young's modulus }=200 \\
\text { Gpa }\end{array}$ & Sonic velocity $=1533 \mathrm{~m} / \mathrm{s}$ \\
\hline Poisson's ratio $=0.3$ & \\
\hline
\end{tabular}

\subsection{Modal Analysis of Tank}

To calculate the natural frequencies and mode shapes of structure, fluid, and coupled system without damping interface a free vibration analysis is carried out in the above specified 3D model. The main objective of 3D analysis is to find the effect of sloshing in the Eigen frequencies through a direct comparison of natural frequencies with and without the effect of free surface. The analysis is repeated for different tank parameters like height, diameter of tank and fluid height by assuming rigid wall boundary conditions so as to study the influence of aspect ratio (h/d) on Eigen frequencies. In order to simulate the convective and impulsive modes, a $3 \mathrm{D}$ analysis is also performed on the same model without free surface effect by selecting a frequency range of $0-10,000 \mathrm{~Hz}$. In the case of sloshing (with free surface effect) two separate frequency range are selected, $0-5 \mathrm{~Hz}$ to extract slosh frequencies (convective mode) and $5-10,000 \mathrm{~Hz}$ to extract the convective and impulsive mode frequencies under sloshing conditions. Further the analysis is extended to rigid and flexible boundary conditions on shallow and rigid tanks.

\subsection{Test Results}

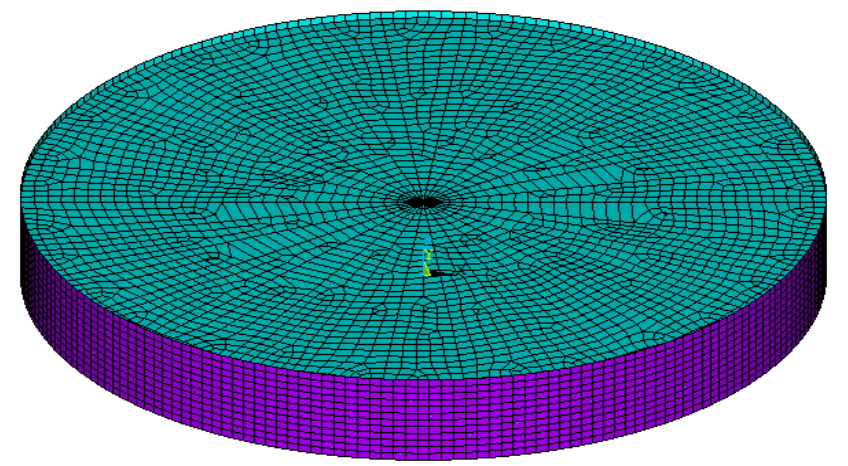

Fig -3: Meshed Shallow tank Model

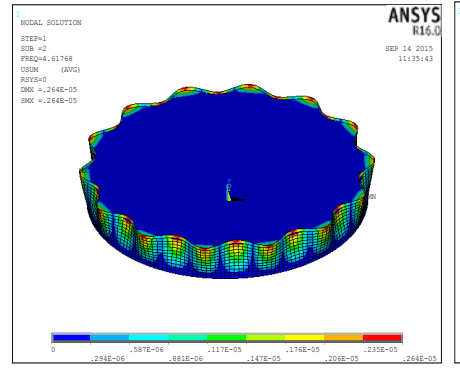

(a)

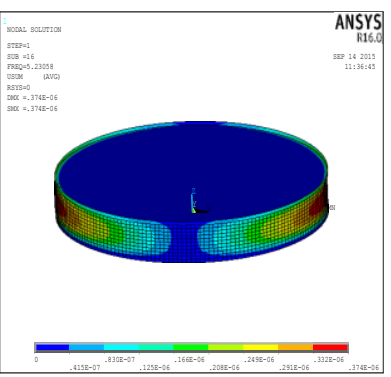

(b)
Fig -4: (a) First convective and (b) First impulsive mode shape of Shallow tank model

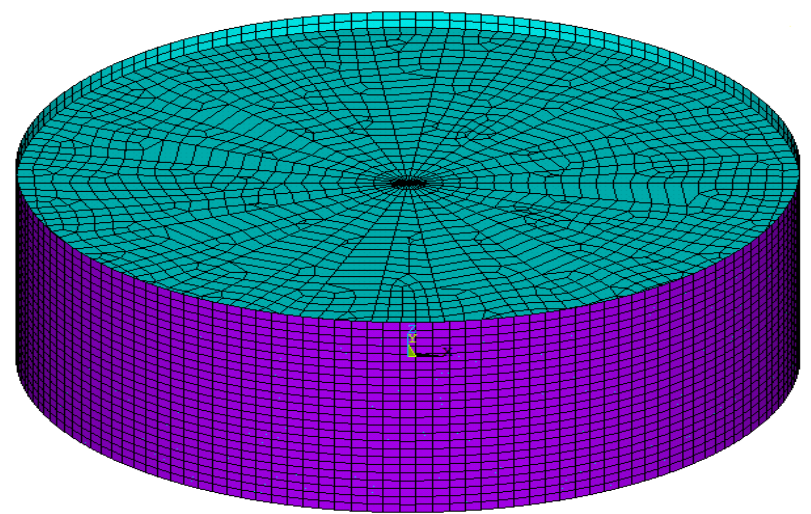

Fig -5: Meshed Tall tank Model 


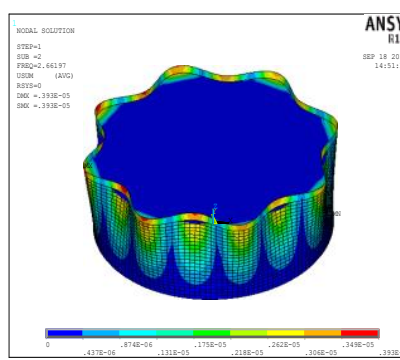

(a)

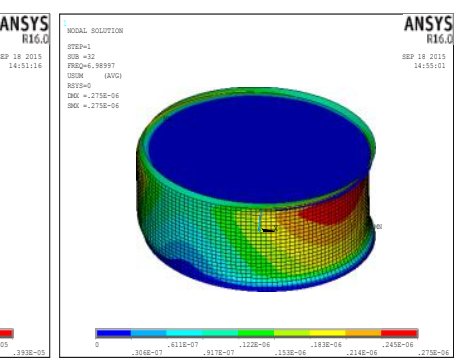

(b)
Fig -6: (a) First convective and (b) First impulsive mode shape of tank model

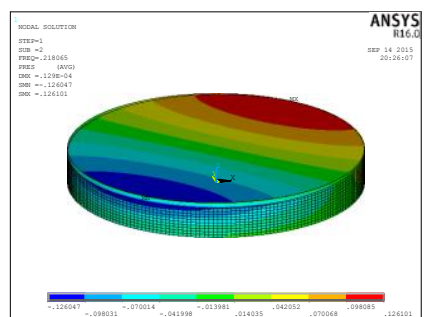

(a)

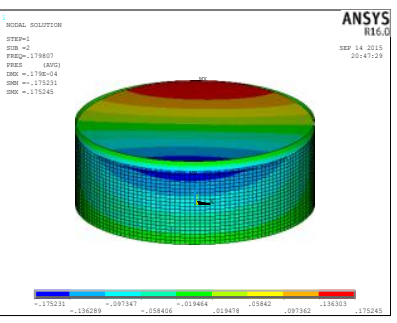

(b)
Fig -7: First Slosh mode of (a) Shallow tank (b) Tall tank model

\section{RESULTS AND DISCUSSION}

\subsection{Effect of fluid mass on convective and impulsive}

\section{modes}

The first convective and impulsive mode frequencies of two tank models with change in height is studied incorporating flexible wall boundary condition and are tabulated in tables.

Table -2: First Convective and Impulsive frequencies of Shallow tank

\begin{tabular}{|c|c|c|}
\hline $\begin{array}{c}\text { Water } \\
\text { height in } \mathrm{m}\end{array}$ & \multicolumn{2}{|c|}{ Frequency in Hertz for shallow tank } \\
\hline & First Convective mode & First Impulsive mode \\
\hline 1 & 7.7221 & 12.1153 \\
\hline 2 & 7.9897 & 7.1370 \\
\hline 2.5 & 7.8254 & 6.3537 \\
\hline 3 & 7.3807 & 5.9301 \\
\hline 4 & 6.17148 & 5.5186 \\
\hline 5 & 5.07813 & 5.3061 \\
\hline 5.5 & 4.6176 & 5.2301 \\
\hline
\end{tabular}

Table -3: First Convective and Impulsive frequencies of tall tank

\begin{tabular}{|c|c|c|}
\hline $\begin{array}{c}\text { Water } \\
\text { height in } \mathrm{m}\end{array}$ & \multicolumn{2}{|c|}{ Frequency in Hertz for tall tank } \\
\hline & First Convective mode & First Impulsive mode \\
\hline 1 & 4.557 & 16.7 \\
\hline 2 & 4.7169 & 10.5913 \\
\hline 3 & 4.8468 & 9.2109 \\
\hline 4 & 4.8851 & 8.7137 \\
\hline 6 & 4.4531 & 8.1334 \\
\hline 9 & 3.2703 & 7.4363 \\
\hline 11 & 2.662 & 6.9899 \\
\hline
\end{tabular}

When fluid is loaded to shallow tank impulsive mode frequency got reduced from $12.1153 \mathrm{~Hz}$ to $5.231 \mathrm{~Hz}$ and convective mode frequency got reduced from $7.722 \mathrm{~Hz}$ to 4.617 Hz. The rate of decrease is more for impulsive mode due to greater participation of fluid mass. It is found that at lower fluid levels convective frequency increase is observed which is due to stiffening of tank wall structure. When the fluid height is gradually increased this convective frequency is reduced. At fluid levels greater than half of tank height, greater fluid mass participation. Thus at lower levels of fluid, convective modes are above the seismic region and it became less dangerous.

\subsection{Design data analysis of shallow and tall tank}

\section{model}

The main aim of this analysis is to conduct a comparitive study on tank models by assuming rigid wall and flexible wall boundary condition. The GSDMA Guidelines for seismic design of liquid storage tanks (2007) have been referred for this analysis. Using the equation for frequency of convective mass:

$$
f=\frac{1}{C_{c}} \sqrt{\mathrm{g} / \mathrm{D}}
$$

Where, $C_{c}$ is the coefficient of convective mode which is found from graph, $D$ is the diameter and $G$ is acceleration due to gravity.

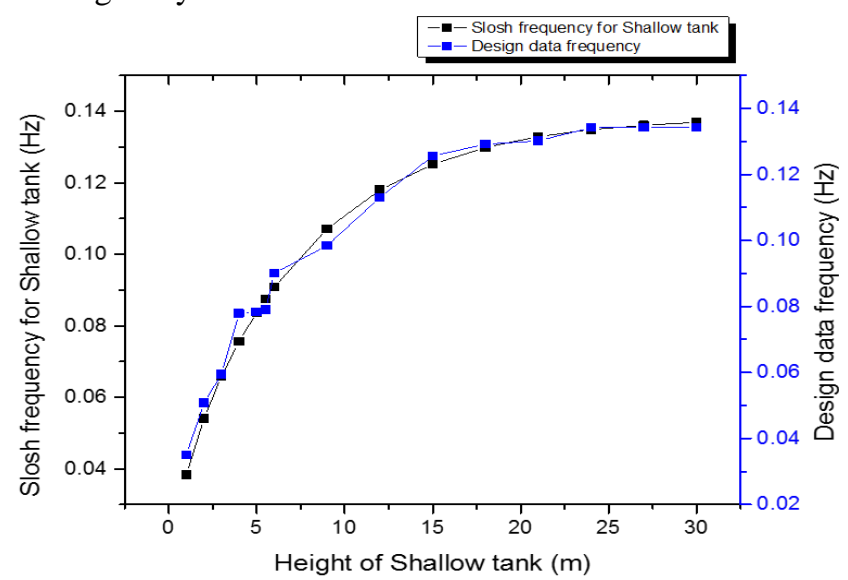

Graph -1: Graphical Representation of Design Data Frequency with FE Frequency for Rigid Wall Shallow Tank

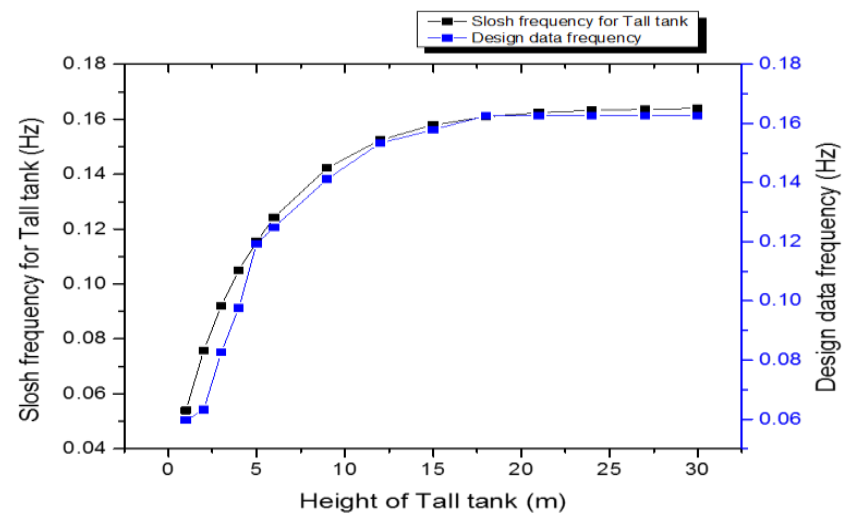

Graph -2: Graphical Representation of Design Data Frequency with FE Frequency for Rigid Wall Tall Tank 
From the graphical representation it is found that design data frequency for rigid wall boundary condition is in close agreement with finite element frequency.

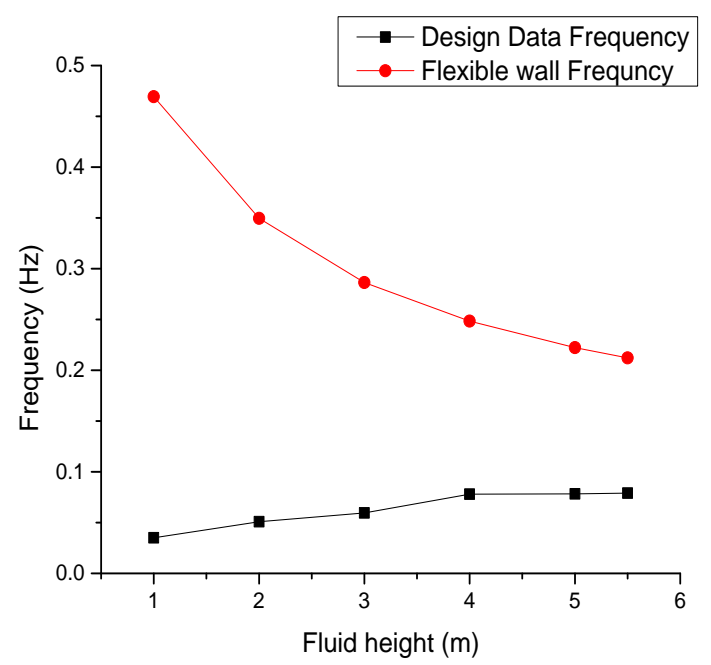

Graph -3: Graphical Representation of Design Data Frequency with FE Frequency for Flexible Wall Shallow Tank

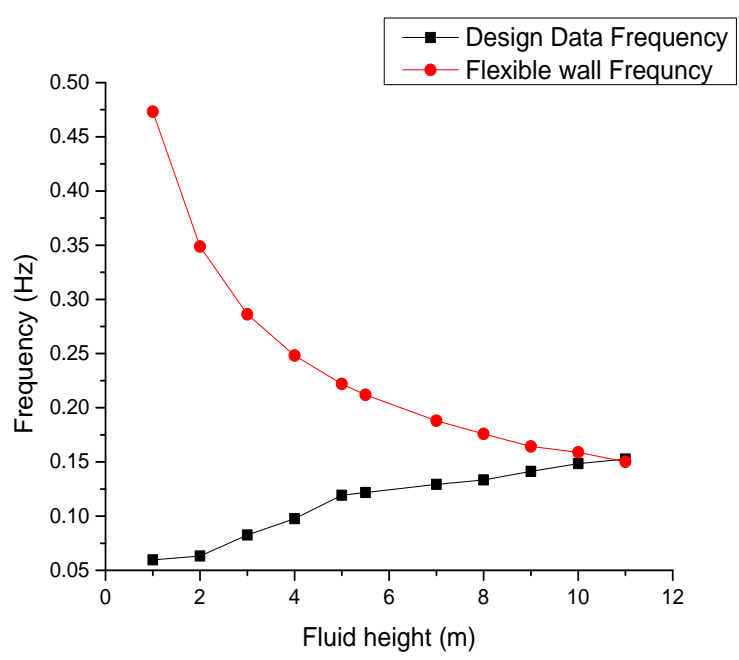

Graph -4: Graphical Representation of Design Data Frequency with FE Frequency for Flexible Wall Tall Tank

The effect of tank wall flexibility increases the frequency (up to $0.5 \mathrm{~Hz}$ ) which is accounted by the tank wall flexibility. This was observed higher for tall tank which is $0.4732 \mathrm{~Hz}$ and for shallow tank it is $0.4693 \mathrm{~Hz}$, which was for a water height of $1 \mathrm{~m}$. When fluid height is increased this frequency was reduced to $0.2121 \mathrm{~Hz}$ for shallow tank and to $0.1501 \mathrm{~Hz}$ for tall tank. Hence flexible wall boundary condition has a significant effect to increase slosh frequency. Shallow tank is having larger diameter than tall tank model. So, sloshing is higher for shallow tank than tall tank and also sloshing decrease with increase in fluid height.

\section{CONCLUSIONS}

It is clear from this parametric study that the effect of fluid level on convective mode, which is the most significant design criterion for seismic resistant structures, and is found to be critical. Hence fluid content in the tank must always be maintained at a safe level as per the design. From the frequency decrease rate we can conclude that the fluid level in the case of tall tank is more critical than the case of shallow tank due to the higher frequency decrease.

$\Delta$ fconvective(shallow) $>\Delta$ fconvective (tall)

$\Delta$ fimpulsive(tall) $>\Delta$ fimpulsive(shallow)

Where,

$\Delta \mathrm{f}=$ change in frequency at different modes

After the comparison of rigid wall with flexible wall it is found that effect due to the flexibility of tank wall, there is an increase in the frequency (up to $0.5 \mathrm{~Hz}$ ) which is accounted by the tank wall flexibility. Hence flexible wall boundary condition has a significant effect to increase slosh frequency which is not considered in the Design Data Book. Shallow tank is having larger diameter than tall tank model. So, sloshing is higher for shallow tank than tall tank and also sloshing decrease with increase in fluid height.

\section{REFERENCES}

[1]. GSDMA Guidelines for seismic design of liquid storage tanks prepared by National Information Centre of Earthquake Engineering, Indian Institute of Technology Kanpur with funding by Gujarat state disaster management authority Gandhinagar (2007)

[2]. M. Moslemi, M.R. Kianoush. "Parametric study on dynamic behaviour of cylindrical ground supported tanks". Engineering Structures 42 (2012): 214-230.

[3]. Jun Zheng Chen. "Generalized SDOF system for dynamic analysis of concrete rectangular liquid storage tank systems". Ryerson University, Toronto (2010)

[4]. A.Ergin, P. Temarel; 2002, "Free vibration of a partially liquid-filled and Submerged, horizontal cylindrical shell" Journal of Sound and Vibration 254(5), PP 951-965

[5]. M. Moslemi, M.R. Kianoush; 2012 "Parametric study on dynamic behavior of cylindrical groundsupported tanks" Engineering Structures, 42, PP 214-230

[6]. Moslem Amiri, Saeed Reza Sabbagh-Yazdi; 2012 "Influence of roof on dynamic characteristics of dome roof tanks partially filled with liquid" Elsevier Ltd 2011, Thin-Walled Structures, 50 PP 56-67

[7]. M. Amiri, S. R. Sabbagh-Yazdi; 2011 "Ambient vibration test and finite element modeling of tall liquid storage tanks" Science Direct, Thin-Walled Structures 49 PP 974-983

[8]. J.C. Virellaa, L.A. Godoy, L.E. Su'arez; 2006"Dynamic buckling of anchored steel tanks subjected to horizontal earthquake excitation" Journal of Constructional Steel Research, 62 PP 521-531

[9]. J.R. Cho, J.M. Song, J.K. Lee; 2001, "Finite element techniques for the free-vibration and seismic analysis 
of liquid-storage tanks" Elsevier, science direct, Finite Elements in Analysis and Design, 37, PP 467483

[10]. F.H. Hamdan; 2000, "Seismic behaviour of cylindrical steel liquid storage tanks" Journal of Constructional Steel Research, 53, PP 307-333

[11]. Juan C. Virella, Carlos A. Prato, Luis A. Godoy; 2008 "Linear and nonlinear 2D finite element analysis of sloshing modes and pressures in rectangular tanks subject to horizontal harmonic motions", Journal of Sound and Vibration 312, PP 442-460

[12]. M. Moslemi, M.R Kianoush, W. Pogorzelski. Seismic response of liquid-filled elevated tanks. Engineering structures 33 (2011): 2074-2084. 